lnd. Health, 1974, 12, 49.

\title{
LOCALIZATION OF INHALED LEAD PARTICLES IN THE RAT LUNG
}

\author{
Hiroko KYONO, Katsunori HOMMA, Takashi NAGATANI, \\ Tadao WATANABE and Kiyoyuki KAWAI \\ National Institute of Industrial Health, Kizuki-Sumiyoshi, Nakahara-ku, Kawasaki \\ and \\ Naka Works, Hitachi, LTD. 882, Ichige, Katsuta, Ibaraki 312
}

(Received March 25, 1974)

\begin{abstract}
Ultrastructural localization of inhaled submicron lead fume was studied on the lungs of rats. The specimens were obtained from two series of experimental exposure to metallic lead fume of $0.3 \mu$ in projected diameter $(\sigma \mathrm{g} 1.31, \mathrm{AMD}=1.1 \mu)$ in concentration of $120 \mathrm{mg} / \mathrm{m}^{3}$ in the first experiment and $0.04 \mu$ in projected diameter $(\sigma \mathrm{g} 1.40$, $A M D=0.19 \mu)$ in concentration of $10 \mathrm{mg} / \mathrm{m}^{3}$ in the second experiment respectively.

Qualitative identification of lead nature of the fine particles deposited in the tissue was parformed with the aid of X-ray micro-analyzer equipped with energy dispersive type detector.

Aside from usual aboundant accumulation of particles in the alveolar macrophage, widespread uptake of lead particles was common findings in the epithelial cells covering the bronchial tree as well as the alveolar surface. In the bronchial epithelium, particles were found more frequently in the periphery, especially in the terminal region, in which non-ciliated cells contained more numerous particles than ciliated epithelium. In the alveolar wall both the type I and type II alveolar epithelium contained lead particles. In every type of the above cells, phagosomes and lysosomes were the main site of localization of particles. Deformation and degradation of fume particles were conspicuous in the cytoplasm especially in the lysosomes and their intercellular biological solubilization were suggested. Significance of the above findings was discussed in relation to possible mechanisms of onset of cellular injury in the respiratory tract.
\end{abstract}

It is generally accepted concept that the pulmonary macrophage plays a significant role in "pulmonary clearance" mechanism of the particulate matter deposited in the alveolar surface., ${ }^{1,23}$ In fact, major fraction of deposited particles are accumulated in the cytoplasm of the alveolar macrophage, after relatively short term exposure to aerosol. On the other hand, however, some smaller fraction may escape scavenging activity of the alveolar macrophage and remains, at least for a while, in the alveolar space as "free particle". Moreover, particles, which are re-liberated from the injured alveolar macrophage and other cells, may also contribute to this "free particle" fraction. A part of those free particles may be 


\section{H. KYONO, K. HOMMA, T. NAGATANI, T. WATANABE AND K. KAWAI}

succeedingly transferred into the lung tissue and the blood stream and may serve as a major source of developing pulmonary and systemic lesions. In this respect, it is important to obtain more detailed information on the fate of "free particle" fraction, which may be escaped from the primary defence mechanism of the lung. From above considerations, distribution of inhaled submicron lead particles in the lung was re-examined under the electronmicroscope. Identification of lead nature of the minute electron-dense particles in the tissue was done with the aid of electron probe microanalysis, which was recently improved in sensitivity.

Past observations on the deposition site of particulate matters in the lung, were usually made in using routine light microscope, and attention has been mainly focused on the aboundant accumulation of particles in the alveolar macrophages. ${ }^{4)}$ In recent years, increasing interest in submicron particles stimulated an effective application of electronmicroscope to observe their behavior in the respiratory tract. In some of those works, it was revealed that a fraction of inhaled submicron particles, for instance, of $\mathrm{TiO}_{3}, \mathrm{CrO}_{3}$ and $\mathrm{NiO}^{5,6)}$ were found in the cytoplasm of type I alveolar epithelium, together with familiar aboundant accumulation in the alveolar macrophage. Sanders et $a l^{7)}$ rendered further substantial support to the above findings in their radioautographic study on the localization of ${ }^{239} \mathrm{PuO}_{2}$ particles in the rat lung. Quite recently, Suzuki et al. ${ }^{8)}$ obtained similar localization of crysotile asbestos fiber, which was insufflated in the rat lung. Interestingly, they also pointed out that some fraction of the asbestos fiber was found in the phagosome of type II alveolar epithelium.

In the course of inhalation experiments to study respiratory deposition of submicron lead fume, we found that intra-cellular localization of the particles was not neccessarily confined to above mentioned cells but was more widespread in the epithelial cells covering the surface of the respiratory tract. In both the type I and the type II alveolar epithelium and in the ciliated and the non-ciliated epithelium, incorporation of the minute lead particles was evidently identified with the aid of X-ray microprobe analysis. The present paper concerns mainly with such localization of the inhaled lead fume particles. Associated ultrastructural alteration of the lung tissue coused by fume inhalation will be described in succeeding paper.

\section{Materials AND Methods}

\section{Experimental animals}

Two series of inhalation were made using every 6 rats for each experiment. They were ceserian origin and weaned in barriered system until the end of 4 th week. After transfer into our animal facilities, they were housed in the stainless steel wire mesh cage and placed in an all fresh air conditioned room with $23 \pm 1^{\circ} \mathrm{C}$ temperature and $50 \pm 5 \%$ relative humidity. Care was taken by a definite personel. Sterilized commercial pellet (CE-2) and sterilized tap water were given ad libitum. 


\section{LEAD PARTICLES IN LUNG}

When the animals were used for inhalation at the nine week old, their body weight were ranging 260 to 340 grams.

\section{Generation of submicron lead fume}

Monodisperse lead fumes were generated with a high frequency induction furnace.9) The purity grade of the metal lead (Ohsaka Asahi Metal Co.) was $99.9999 \%$. The mean concentration of the lead fume was calculated from the amount of lead trapped on the filter paper in the monitoring impactor. Particle size distribution of the fume was meaured with electronmicroscopic method. For collection of the lead fume on the specimen grid, an inertia-separate type impactor was used. Operating conditions of the furnace, size distribution and mean concentration of the fume thus obtained were listed in Table 1 together with experimental designs in two series of inhalation.

Table 1. Experimental conditions.

\begin{tabular}{|c|c|c|c|}
\hline & 1st experiment & \multicolumn{2}{|c|}{ 2nd experiment } \\
\hline Charge weight of metal lead & $42.0 \mathrm{~g}$ & \multicolumn{2}{|l|}{$42.0 \mathrm{~g}$} \\
\hline Temperature at metal surface & $1100^{\circ} \mathrm{C}$ & \multicolumn{2}{|c|}{$920-940^{\circ} \mathrm{C}$} \\
\hline Power of furnace & $3.2 \mathrm{kV}$ & \multicolumn{2}{|l|}{$2.8 \mathrm{kV}$} \\
\hline Carrier gas/min. & $0.81 \mathrm{~N}_{2} / 20.01$ air & \multicolumn{2}{|c|}{$1.51 \mathrm{~N}_{2} / 20.01 \mathrm{air}$} \\
\hline Particle size & & \multirow{4}{*}{\multicolumn{2}{|c|}{$\begin{array}{l}0.04 \mu \\
0.19 \mu \\
1.40\end{array}$}} \\
\hline CMD & $0.3 \mu$ & & \\
\hline AMD & $1.1 \mu$ & & \\
\hline$\sigma \mathrm{g}$ & 1.31 & & \\
\hline Mean concentration of particle & $120 \mathrm{mg} / \mathrm{m}^{3}$ & \multicolumn{2}{|c|}{$10 \mathrm{mg} / \mathrm{m}^{3}$} \\
\hline Inhalation chamber & & \multirow{4}{*}{\multicolumn{2}{|c|}{$\begin{array}{l}0.3 \mathrm{~m}^{3} \\
22.5^{\circ} \mathrm{C} \\
38 \%\end{array}$}} \\
\hline Volume & $0.3 \mathrm{~m}^{3}$ & & \\
\hline Temperature & $22.5^{\circ} \mathrm{C}$ & & \\
\hline Humidity & $38 \%$ & & \\
\hline Exposure time & $90 \mathrm{~min}$ & $90 \mathrm{~min}$ & $330 \mathrm{~min}$ \\
\hline \multicolumn{4}{|l|}{ Animal sacrificed } \\
\hline hours after the termination of inhalation & $0,3,24$ & 0,3 & 0 \\
\hline
\end{tabular}

\section{Method of inhalation}

A cylindrical head exposure type inhalation chamber of $0.3 \mathrm{~m}^{3}$ capacity was used, which allows to place 6 rats simultaneously. Generated lead fume was introduced into the chamber under continuous monitoring of relative concentration with a digital dust counter of Shibata S-633 type. When. the stable state in fume concentration was attained, 6 rats were charged to inhalation. Duration of exposure time was $90 \mathrm{~min}$ in the first experiment and 90 and $330 \mathrm{~min}$ in the second experiment respectively. After termination of inhalation, the rats were kept in an another room until the time of preparation and provided again with pellet and 


\section{H. KYONO, K. HOMMA, T. NAGATANI, T. WATANABE AND K. KAWAI}

water. Relative fume concentration in the inhalation box was monitored continuously during the whole course of inhalation and particle size were checked every $20 \mathrm{~min}$.

\section{Tissue preparation}

Every two animals were sacrificed at 0,3 and $24 \mathrm{hr}$ after the termination of $90 \mathrm{~min}$ exposure in the 1st experiment, and at 0 and $3 \mathrm{hr}$ after $90 \mathrm{~min}$ exposure and just after $330 \mathrm{~min}$ exposure in the 2nd experiment. Under deep anesthesia with an intraperitoneal injection of sodium pentobarbital, the chest was opened and a horizontal slice of a few $\mathrm{mm}$ thick was cut from the middle part of the left lung including hilar bronchi. The slice was immediately cut into $1 \mathrm{~mm}$ cubes and fixed in $5 \%$ glutaraldehyde in $0.1 \mathrm{M}$ cacodylate buffer $(\mathrm{pH} 7.4)$ at $0^{\circ} \mathrm{C}$. After two hours fixation, the blocks were washed in cold cacodylate buffer containing isotonic sucrose and postfixed in cold $1 \%$ osmium tetroxide in s-collidine buffer at $\mathrm{pH}$ 7.4. Blocks were dehydrated through graded ethanol and embedded in Epon. Both stained (uranyl-acetate and / or lead-citrate) and unstained ultrathin sections were examined with Hitachi HU-11A electron microscope. Light microscopic observations were also made on routine buffered formalin-fixed, paraffin embedded section stained with H.E. as well as on $1 \mu$ thick sections from the Epon blocks stained with Giemsa.

\section{- X-ray microanalysis}

For electron probe microanalysis, unstained Epon sections of 1000 to $2000 \AA$ in thickness were placed either on the surface of a well polished carbon rod or on a naked nickel mesh. In a couple of cases, a section was mounted on a hand made single hole carbon mesh. Section were examined in a scanning electon microscope (Hitachi SSM-2 or HSM-2A) equipped with a energy dispersive X-ray spectrometer (EDAX). Identification of the element was performed with accelerating voltage of 20 to $40 \mathrm{kV}$ and specimen currents of $2 \times 10^{-11} \mathrm{~A}$ or $6 \times 10^{-11} \mathrm{~A}$.

\section{Original lead particle}

Original lead particle obtained from the inhalation chamber was monodisperse and rather uniform and shown in Table 1 . They were almost spherical in shape and their surface were quite smooth (Figs. 1a, b). Under the transmission electronmicroscope they appeared to be homogenous opacity. X-ray microanalysis of a $0.3 \mu$ sized particle gave sharp peak of characteristic $\mathrm{L}_{\alpha}$ and $\mathrm{L}_{\beta}$ of lead (Figs. 1c, d). Examining thin section, a small number of extracellular "free particles" were found in the alveolar space or onto the alveolar wall attached. They were quite identical with the original particles in shape, size and electron opacity and gave typical peak of $\mathrm{L}_{\alpha}$ and $\mathrm{L}_{\beta}$ of lead in point analysis (Figs. 2a, b).

\section{RESULTS}

When the chest was opened, the lung showed slight athelektasis. Under 


\section{LEAD PARTICLES IN LUNG}

routine light microscope, bronchi of middle to small size showed sign of contraction, and protrusion of the bronchial epithelia was evident. Shortly after the inhalation was terminated, the alveolar space were apparently free from exudate and macrophage mobilization, under routine light microscope. Later, after $24 \mathrm{hr}$, there were disseminated area of fluid accumulation in the athelectatic alveolar space. Mobilization of alveolar macrophage were remained still in a limited extent.

Electronmicroscopically, only a small number of inhaled lead particle were found "free" in the alveolar space in every stage after exposure. The majority of such "free particles" were associated with cellular debris and lattice like materials, and appeared to be liberated from degenerated cellular element. They were usually clustered, somewhat irregular in shape and the surface lost their original smoothness (Figs. 3a, b, c).

As expected, more of less aboundant accumulation of dense particles were found in the alveolar macrophages. In earlier stage after the termination of exposure, particles distributed more coasely in the cytoplasm and solitary particles with or without sorrounding vesicles were quite often encountered (Fig. 4a). Later the electron dense particles were usually found clustered in phagosomes and lysosomes. Some of these particles retained their original character in respect to size, shape and smoothness in surface, however, the majority of the particles revealed florid transformation of their morphological characteristics (Fig. 4b). They were far irregular in shape and size as compared to original fume. They lost their smoothness of the marginal outline and appeared to be burred and fine pinsel-like spicles were discernible at higher magnification. Some of these particles appeared to lost their homogeneity and more finer granulated substructure were frequently recognized under higher magnification. Apparently, some particles tended to break into more smaller fragments. Some particles appeared, on the other hand to be fused to each other in forming more coarse irregular particle (Figs. 3c, 4c). Thus in the cytoplasm of the alveolar macrophage, size distribution of inhaled lead fume was far broader than that of original, and differentiation was sometimes difficult whether a picture of an alveolar macrophage was obtained either from the first or second series, especially in their later stage after the termination of exposure. $\mathrm{X}$-ray microanalysis were also made of some of these particles in the alveolar macrophages and gave constant positive results (Figs. $4 \mathrm{~d}, \mathrm{e}$ ).

At $3 \mathrm{hr}$ after the exposure, electronmicroscopic morphometry revealed slight increase in alveolar wall thickness, which proceeded to $16.5 \%$ increase after $24 \mathrm{hr} .{ }^{10}$ ) In accordance with this finding, edema in the interstitium and swelling of type I alveolar epithelium were evident under the electronmicroscopy. Cytoplasm of this epithelium was irregularly thickened, and cytoplasmic projections were more frequent than usual. Single or small cluster of the lead particles were occasionaly seen embraced between two such protrusions (Figs. 5a, b).

$\mathrm{X}$-ray microanalytically positive dense particles were found frequently in the 


\section{H. KYONO, K. HOMMA, T. NAGATANI, T. WATANABE AND K. KAWAI}

cytoplasm of type I alveolar epithelium. They were single or a few in clusters, and located in a small vesicles or in the lysosome-like granules with limiting membrane (Figs. 5c, d, e, f).

The type II alveolar epithelium showed sign of alteration from early stage after exposure. Increase in electron density and vaculolation of the cytoplasm were main features. Most cells contained a large number of osmiophilic inclusions, which showed disarrangement and degradation of their usual lamellar structure (Fig. 6a). This type of epithelium contained also fine electron dense particles very frequently as seen in the type I epithelium. They were less frequently clustered, small in size ranging about 30 to $50 \mathrm{~m} \mu$ in size even in the experiment I. The most frequent localization was in the osmiophilic inclusions, especially just inside of their limiting membrane, and tend to be arranged as array along the membrane. In the specimen from 330 minutes exposure, almost every type II cells contained one or more particles. In the lysosome-like granules and in the vacuoles, particles were also located as well (Figs. 6b, c, d). Areal electronmicroanalysis of particle contained osmiophilic inclusions were sometimes positive, however, point analysis of a solitary minute particles was only occasionary succesful and require further confirmation (Figs. 6e, f).

Morphological alterations in the bronchi, especially of smaller size, were evidently noticed 3 hours after exposure. Vacuolation and/or vesiculation of the cytoplasm were main feature, which were more predominated in the non-ciliated cells. Darkening of cytoplasm associated with lace-like dilatation of endoplasmic reticulum were formed occasionaly in basal cells (Figs. 7a, b). The lumina of some bronchioles was filled with cluster of desquamated bronchial epithelia, lead particles laden alveolar macrophages, cellular debris and desquamated cilia (Figs. 7a, 8a). Solitary or aggregated particles were found intercalated between the cilia and the microvili (Figs. 8b, c, 12a, b). In the cytoplasm, dense particles were found chiefly in the lyososome. They were usually multiple, up to about 20 in number in a lysosome, ranging 30 to $60 \mathrm{~m} \mu$ in size (Figs. 9a, b, c). Most of the particles in vesicles or vacuoles were solitary and somewhat larger than those in the lysosomes. (Figs. 8b, 9d). Sometimes they were up to 200 to $300 \mathrm{~m} \mu$ in the first experiment. Solitary particles were sometimes found in the apical part of the intercellular space (Figs. 10a, b). After prolongation of exposure in the second experiment, almost all of epithelia of the peripheral bronchi contained more or less particles. In this stage morphological alterations became more marked, and in some places of peripheral bronchi, intracellular edema developed in the basal part of the epithelial lining (Fig. 11). In such edematous area, a few to several fine particles were floating occasionally. In the larger bronchi, the epithelial changes were slighter than in the peripheral bronchi, and number of the intracellular particles were less frequent. 


\section{LEAD PARTICLES IN LUNG}

\section{Discussion}

Morphological observations on the fate of particulate matter inhaled in the lung has long been focused on the phagocytotic function of the alveolar macrophage. In fact, marked accumulation of particles in those cells, when examined in vivo and in vitro, has been considered as a morphological evidence that scavenging activity of this cell system is an essential basis of primary defense mechamisms. of the lung. Accerlation of pulmonary lesions due to several kinds of insult were also explained by decreased "pulmonary clearance", which are shared mainly by these cells.

On the other hand, however, little has been known on the fate of some smaller fraction of the particles, which may escaped from scavenging activity of pulmonary macrophage. There has been also no conclusive morphological evidence to illustrate the source and invading route of particulate matters from the alveolar space into the interstitial tissue of the lung.

Our observations described above have clearly shown that some, at least a part, of inhaled submicron lead fume fraction were incorporated into the epithelial cells overlying the surface of the respiratory tract. Although the number of particles in those epithelium was far smaller than those accumulated in alveolar macrophage, it should be emphasized that occurrence of this phenomenon was reproducible, and dependent of duration of exposure. When exposure was prolonged to $330 \mathrm{~min}$ in the second experiment, at least one or more lead particles could be detected in practically all of the epithelial cells examined, down from the peripheral bronchioli to the alveolar surface. Considering remarkable thinness of electronmicroscopic sections, this widespread and frequent localization allowed to us conclude that this process may be one of the essential and basic occurence in this two sereis of experimental inhalation of submicron lead fume.

It is also noteworthy that the uptake of lead fume may not necessarily be confined to any definite type of epithelium but more or less a common character in every type including ciliated and non-ciliated bronchial epithelium as well as type I and type II epithelium at the alveolar wall. Uptake of particulate matter in any respiratory epithelium has long been a subject of controversary, when observations were made under light microscope. There has been yet no conclusive idea concerning the kind of epithelium, the intracellular site of localization and even the capability per se. Recent application of electronmicroscopic observation is now a hopefull way to elucidate more exact information on this subject. Conditions to facilitate this process should be further studied.

Several recent observations coincided in that the type I alveolar epithelium are able to uptake particles of several kinds of oxide of heavy metal. Suzuki et $a l .^{8)}$ also found fine fibril of insufflated asbestos in this epithelium. Our observation confirmed also those findings. Remarkable formation of cytoplasmic protrusions, 
which were frequently embracing lead particles between them, are highly suggestive of phagocytic function of this type of epithelium. Here again, lysosomelike granules and vacuoles were the most usual sites of localization of the particles.

On the type II alveolar epithelium, there has been some discrepancies in past descriptions. Ladman and Fineley ${ }^{11)}$ reported the ingestion of Thorotrast by type II cells, and they found the particles in the cisternae of the ER and to a lesser extent in the lamellar inclusions. They suggested the capacity for phagocytosis of type II cells in a limited extent. On the other hand, Sanders et al. ${ }^{7)}$ who noticed widespread deposition of several kinds of metal oxide particles in this type of epithelium, did not find any deposition in the type II epithelium. Suzuki et al. ${ }^{8)}$ described intracytoplasmic location of insufflated crysotile asbestos in this epithelium. Ogata et al. ${ }^{12)}$ described also uptake of fine lead fume by this cell, quite recently. Our finding disclosed more widespread and constant deposition of particles in this cell system. Morphology and positive results in X-ray microanalysis are indicating lead nature of those particles. Noteworthy was also intimate association of particles with the osmiophilic inclusions, which frequently showed sign of disintegration. Sorokins' suggestion ${ }^{13)}$ for the lysosomal nature of osmiophilic inclusions by his cytochemical study is interesting in this respect. Those recent observations may lead us to a conclusion that the type II alveolar epithelium may be able to uptake inhaled particles under circumstaces.

Uptake of particulate matters by bronchial epithelium has long been a subject of sporadic discussion with still inconclusive and discrepant results under routine light microscopic observations. Even after introduction of electronmicroscopic observations, attention or description on this subject has been escaped in the above mentioned recent literatures. In our present observations, as mentioned above, uptake of the inhaled lead fume was more or less general and constant finding in every type of bronchial epithelium. Lysosomes and vacuoles were the main site of accumulation of fine particles in those cells. Endocytotic activity of the bronchial epithelium, has not been described in the above mentioned literatures. Widespread localization of inhaled submicron lead fumes in almost all types of epithelium covering the respiratory tract may imply that this process is shared by those cell system, which may be derived from phylogenically common origin. If this assumption were true, it may also relevant to the phylogenical identity of the type II alveolar epithelium to the type I alveolar epithelium.

In our earlier observations, intracytoplasmic deformation and disintegration of lead fume were noticed in the lysosomes of the alveolar macrophage of rats which received intratracheal insufflation of lead fume in rather large amount. ${ }^{14)}$ In this experiment, association of needle-like crystal with deformated lead particles were conspicuous in the lysosomes and regarded as a suggestive picture of their solubilization in situ (Fig. 13a). In the present inhalation study, quite similar deformation of the lead particles were also evident, though crystal formation was remained 


\section{LEAD PARTICLES IN LUNG}

in far lesser extent (Figs. 9e, 13b). From the above findings, it is suggested that metallic particles, even if they were comparatively insoluble in vitro, might be dissolved in the cytoplasm of tissue cells, especially in the lysosomes where the most usual site of accumulation of the particulate matter in the cells. Suspected high acidity and reactivity to foreign particles of this organella might be the most favorable explanation for this "biological solubilization" of metallic particles in vivo.

There has long been no adequate explanation of well known fact that more or less evident absorption for metal into the blood is occuring during and after exposure to metallic fume. This was also true in cases of heavy metals, which are comparatively insoluble at the acidity physiologically found in tissue fluid. Above considerations from our present findings may somehow relevant to explain this discrepancy. Direct trans-capillary absorption of fine particles of lead was stressed by Ogata et al., in using rather high concentration of lead fume generated by an atomic absorption spectrophotometer using acetylene gas as fuel. In the present observations on over 2000 plates practically no lead particles was found in the basement membrane as well as in the endothelium of capillary throughout the experiments. This discrepancy may be related to the physicochemical nature of lead particle used and method to generate them.

In considering mechanisms, how the metallic fume exert its injurous effects upon the alveolar macrophage after phagocytized, significance of the above "intralysosomal solubilization" could be also taken into account. The most acceptable explanation at present may be that structural disintegration or functional impairment of the lysosomes and succeding leakage of their enzymes, as indicated in other toxic particles. ${ }^{15)}$

Similar considerations may also be valid to explain the more or less evident morphological alterations in the overall epithelial system of the respiratory tract. It has been hitherto assumed, without any definite evidence, that metallic particles excert their injurous effect after they were dissolved in some way in the alveolar space and or on the surface of respiratory tract. From our present findings, widespread uptake of fine particles in every type of the epithelium of the respiratory tract, may render more realistic and acceptable explanation to possible onset of injury in those cell systems. This explanation appeared to be quite favorable in bronchial epithelium, which assumed to be separated principally from direct contact with the particles deposited or transported on the surface of the bronchial lumina. Interestingly, changes in the bronchial epithelia were appeared to be roughly parallel to the number and frequency of lead particles contained. In fact, the most remarkable pictures were seen in the non-ciliated type of bronchial epithelium, in which fine particles were the most numerous. This situation was less prominent in the ciliated type of epithelium. Moreover, more marked alterations were found in the peripheral bronchioli than in the proximal larger bronchi. Thus widespred 


\section{H. KYONO, K. HOMMA, T. NAGATANI, T. WATANABE AND K. KAWAI}

localization and possible intracellular solubilization of inhaled submicron lead particles may be highly significant factors, which should be taken always in account when elucidation of injury in the respiratory tract are considered. Reliberation of particles from the degenerating alveolar macrophage as well as from the epithelial cells and possible re-uptake by those cell systems, may well be further complicating factor in analysing the fate of particle in this system, including their deposition and clearance. Translocation of the particles into the tissue and into the general circulation are await further studies.

The authors wishes to express their sincere gratitude to Miss. S. Simizu in this institute and to Mr. M. Hamano of the Application Laboratory, Naka Works, Hitachi, Ltd. for their cooperation.

\section{REFERENCES}

1) Karrier, H.E. (1960). J. Biophys. Biochem. Cytol., 7, 357.

2) Sanders, C. L. (1969). Arch. Environ. Health, 18, 904.

3) Bingham, E., Barkley, W., Zerwas, M., Stemmer, K. and Tayler, P. (1972). Arch. Environ. Health, 25, 406.

4) Brundelet, P. J. (1967). Inhaled Particles and Vapours II (Edited by Davies, C. N.) p. 49-52. Pergamon Press, Oxford.

5) Elo, R., Määttä, K., Uksila, E. and Arstila, A. V. (1972). Arch. Pathol, 94, 417.

6) Sanders, C.L., Jackson, T. A., Adee, R. R., Powers, G. J. and Wehner, A. (1971). Arch. Intern. Med., 127, 1085.

7) Sanders, C. L., Adee, R. R. and Jackson, T. A. (1971). Arch. Environ. Health, 22, 525.

8) Suzuki, Y., Churg, J. and Ono, T. (1972). Am. J. Pathol., 69, 373.

9) Homma, K. (1966). Ind. Health, 4, 129.

10) Kyono, H., Homma, K. and Kawai, K. (1974). The 47th Meeting of Jap. Assoc. Ind. Health p. 158. (in Japanese)

11) Ladman, A. J. and Finley, T. N. (1966). Anat. Rec., 154, 372.

12) Ogata, M., Tanaka, A, Yokomura, E., Kumashiro, K., Yamamoto, S. and Seno, S. (1973). Acta. Med. Okayama, 27, 211.

13) Sorokin, S. P. (1966). J. Histochem. Cytochem., 14, 884.

14) Kawai, K. and Nozaki, Y. (1968). Igaku no Ayumi, 65, 211. (in Japanese)

15) Ed. by Dingle, J. T. (1973). Lysosomes in Biology and Pathology, vol. III. Noth-Holland Pub. Co. Amsterdam. 


\section{LEAD PARTICLES IN LUNG}

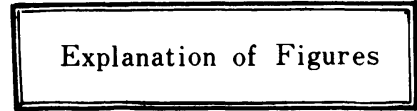

Key to abbreviations

$\begin{array}{llll}\mathrm{Al}, & \text { alveolar lumina } & \mathrm{Er}, & \text { erythrocyte } \\ \mathrm{Am}, & \text { alveolar macrophage } & \mathrm{Ep}-\mathrm{I}, & \text { type I alveolar epithelium } \\ \mathrm{Bc}, & \text { basal cell } & \mathrm{Ep}-\mathrm{II}, & \text { type II alveolar epithelium } \\ \mathrm{Br}-1, & \text { bronchial lumina } & \mathrm{Ly}, & \text { lysosome } \\ \mathrm{Bm}, & \text { basement membrane } & \mathrm{Nc}-\mathrm{Ep}, & \text { non-ciliated epithelium } \\ \mathrm{Ca}, & \text { capillary } & \mathrm{N}, & \text { nucleus } \\ \mathrm{Ci}, & \text { cilium } & \mathrm{Oi}, & \text { osmiophilic inclusion } \\ \mathrm{C}-\mathrm{Ep}, & \text { ciliated epithelium } & \mathrm{Ph}, & \text { phagosome } \\ \mathrm{Ed}, & \text { endothelium } & \mathrm{V}, & \text { vesicle }\end{array}$


H. KYONO, K. HOMMA, T. NAGATANI, T. WATANABE AND K. KAWAI

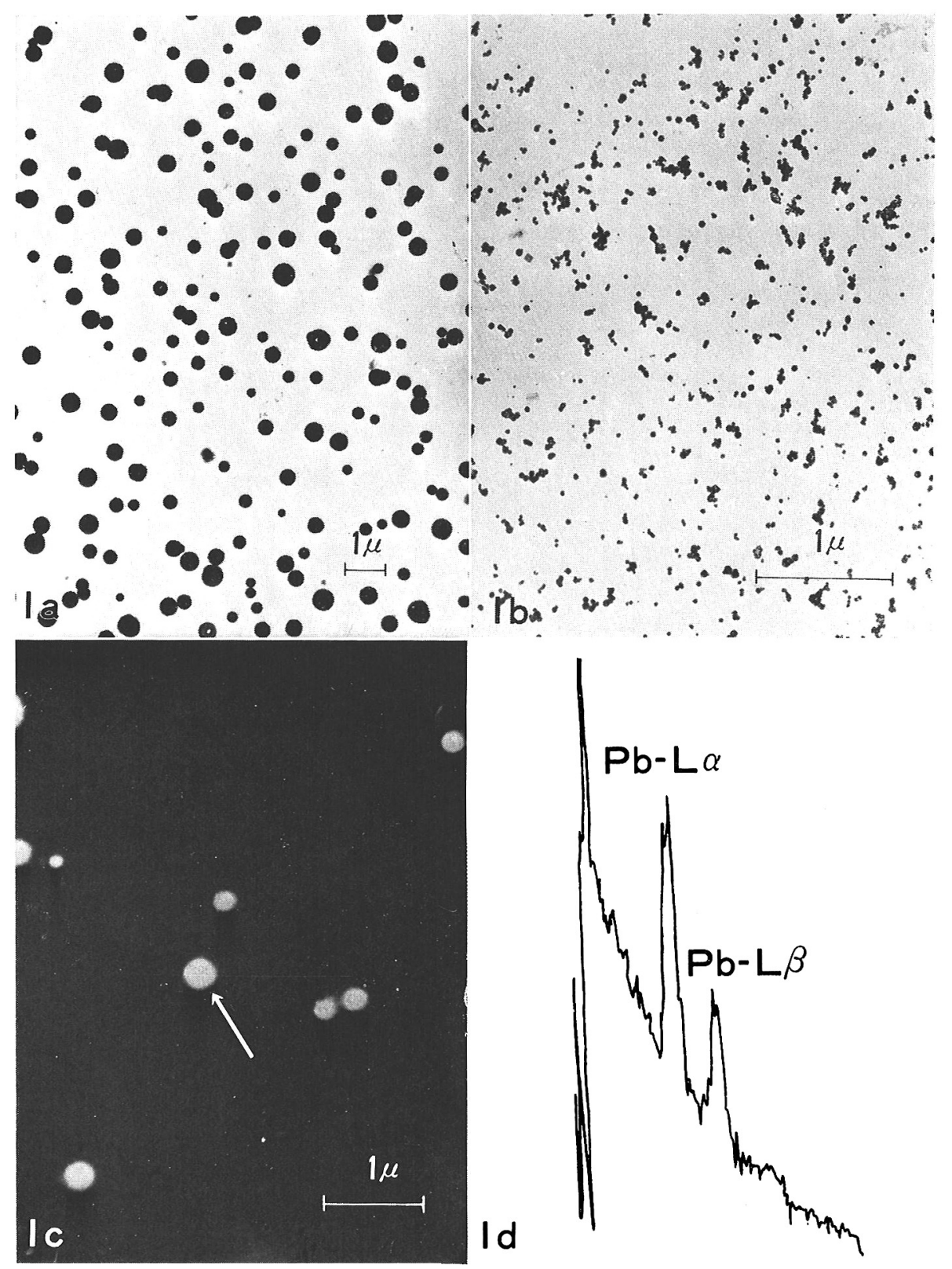

Fig. 1. Original metallic lead particles before inhalation.

Fig. 1(a) Count median diameter: $0.3 \mu$ (Exp. 1)

Fig. 1(b) . Count median diameter: $0.04 \mu$ (Exp. 2)

Fig. 1 (c) Secondary electron image of $0.3 \mu$ particle. Accelerating voltage: $20 \mathrm{kV}$, Specimen current: $2 \times 10^{-11} \mathrm{~A}$ Arrow indicates the point of analysis.

Fig. 1(d) Microprobe X-ray analysis for Fig. 1(c). 


\section{LEAD PARTICLES IN LUNG}
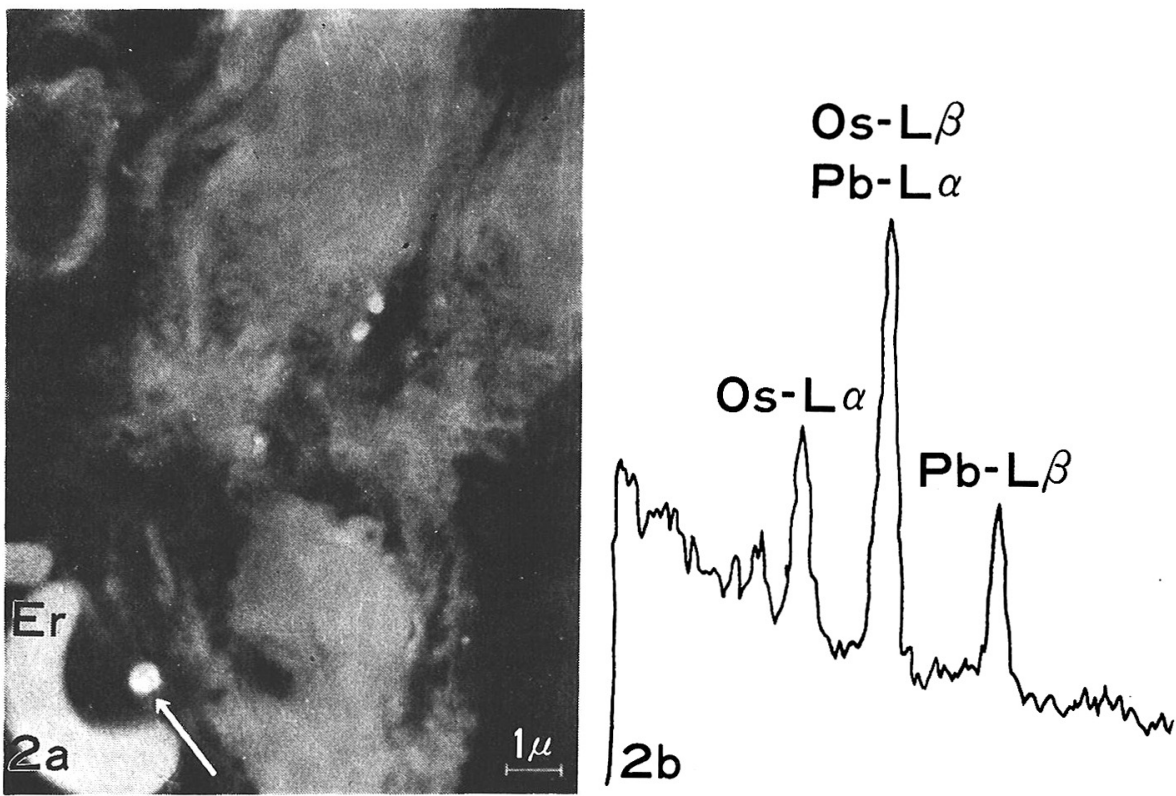

Fig. 2. Lead particles attached on the alveolar wall.

Fig. 2 (a) Secondary electron image of $0.3 \mu$ particle. (Exp. 1) Immediately after inhalation. Arrow indicates the point of analysis.

Fig. 2(b) Microprobe X-ray analysis for Fig. 2(a).

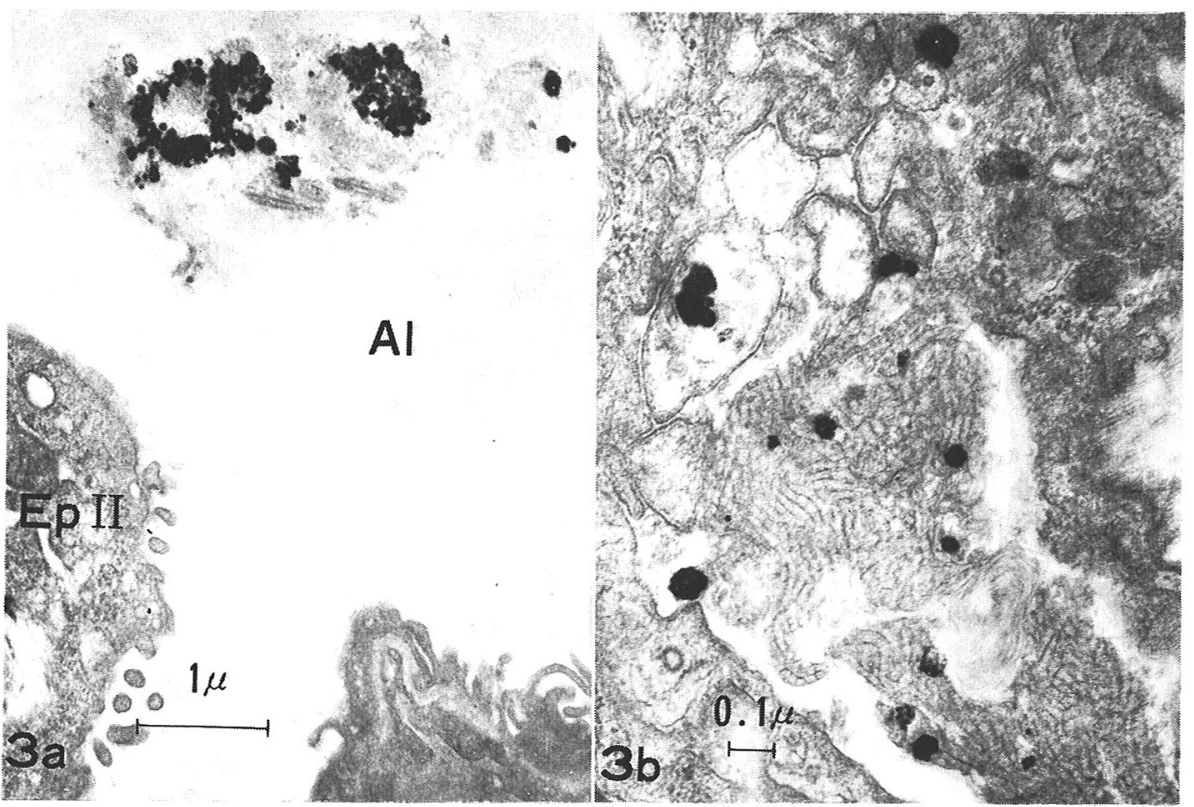

Fig. 3. Free lead particles in the alveolar space.

Fig. 3(a) Clustered particles associated with cellular debris. (Exp. 2)

Immediately after continuous inhalation for $330 \mathrm{~min}$.

Fig. 3(b) Particles are trapped in the lattice like materials. (Exp. 1, 3 hr later) 
H. KYONO, K. HOMMA, T. NAGATANI, T. WATANABE AND K. KAWAI

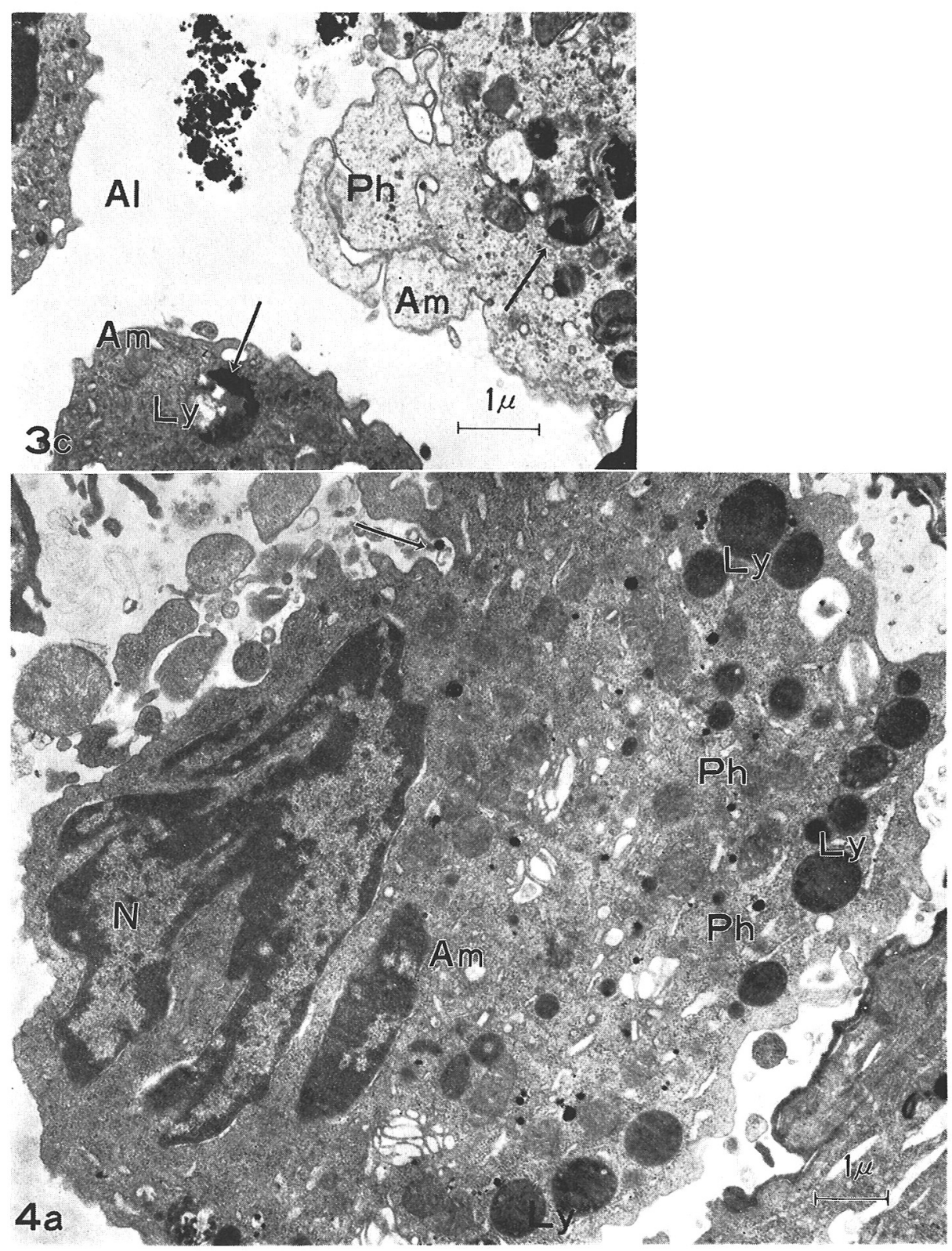

Fig. 3(c) Clustered particles in the alveolar space. Notice the similarity of the particles in the alveolar macrophages. (arrows) Solitary particle is also lies within a phagosome.

Fig. 4. Lead particles in alveolar macrophage.

Fig. 4(a) A number of solitary, smooth surfaced particles are phagocytized in the alveolar macrophage. Immediately after inhalation.

(Exp.1) Arrow indicates a particle outside of the cell. 


\section{LEAD PARTICLES IN LUNG}
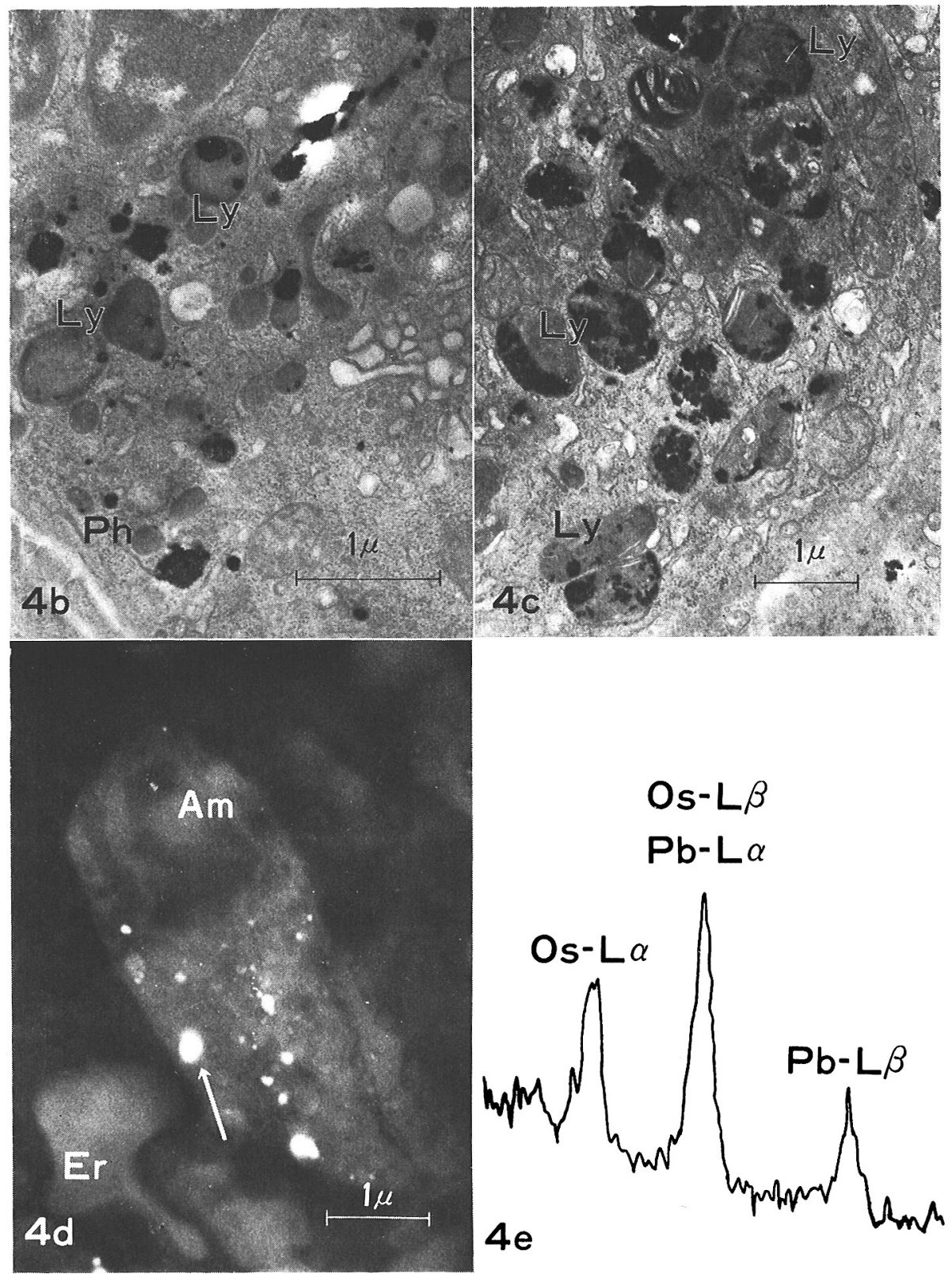

Fig. 4(b) Transforming particles are found in phagosomes and lysosomes, 3 hr after inhalation. (Exp. 1, unstained)

Fig. 4(c) Very minute particles are clustered within lysosomes. Immediately after continuous inhalation for $330 \mathrm{~min}$. (Exp. 2)

Fig. 4(d) Secondary electron image of an alveolar macrophage. Intracellular lead appears as small white dots. Arrow indicates the point of analysis. (Exp. 1, $3 \mathrm{hr}$ later)

Fig. 4(e) Microprobe X-ray analysis for Fig. 4(d). 
H. KYONO, K. HOMMA, T. NAGATANI, T. WATANABE AND K. KAWAI

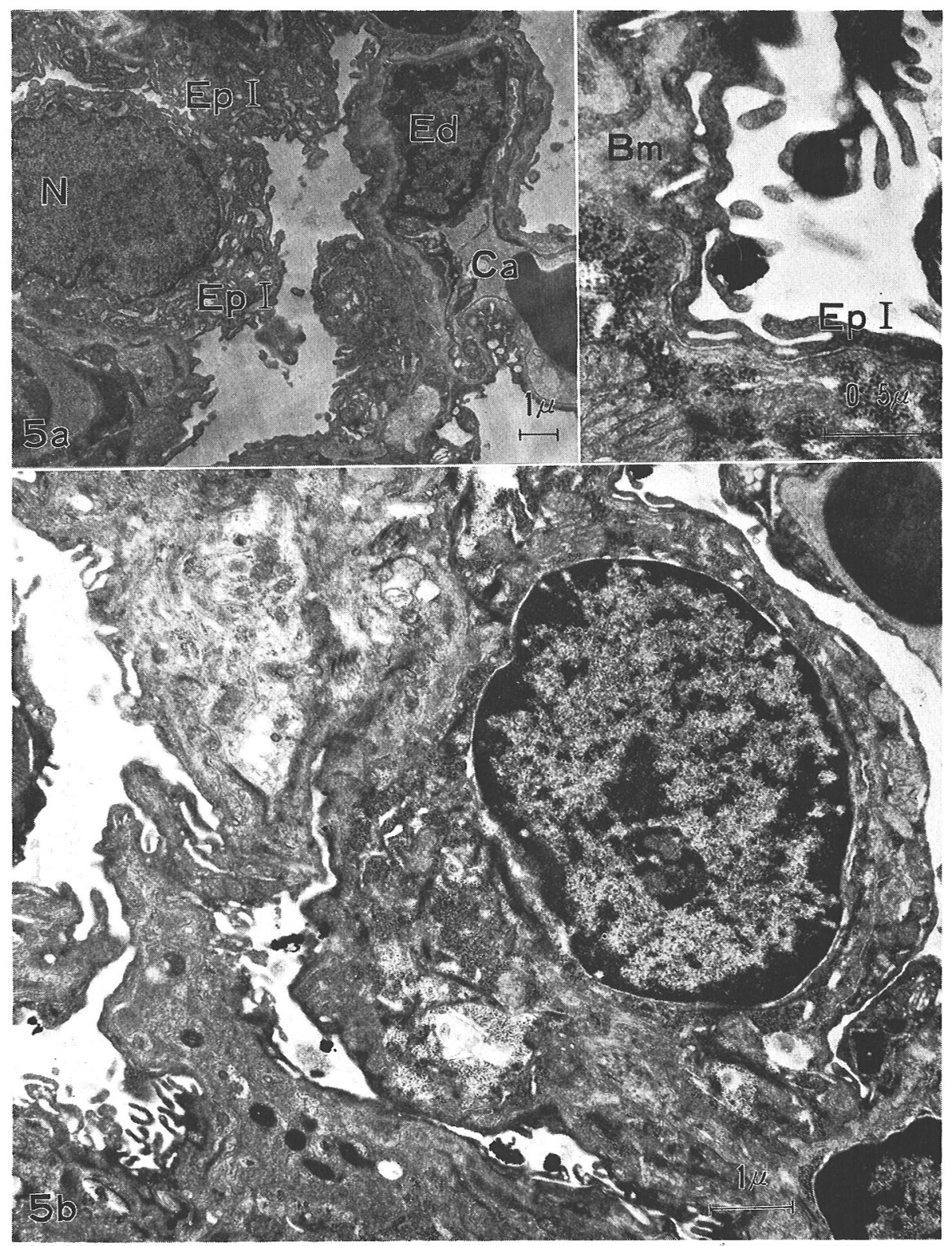

Fig. 5. Lead particles in the type I alveolar epithelium.

Fig. 5(a) Lace-like degeneration of cytoplasm of type I alveolar epithelium. (Exp. 1, 24 hr later)

Fig. 5(b) Lead particles are embraced between cytoplasmic protrusions of type I alveolar epithelium (see upper right insert). (Exp. 1, $3 \mathrm{hr}$ later) 
LEAD PARTICLES IN LUNG

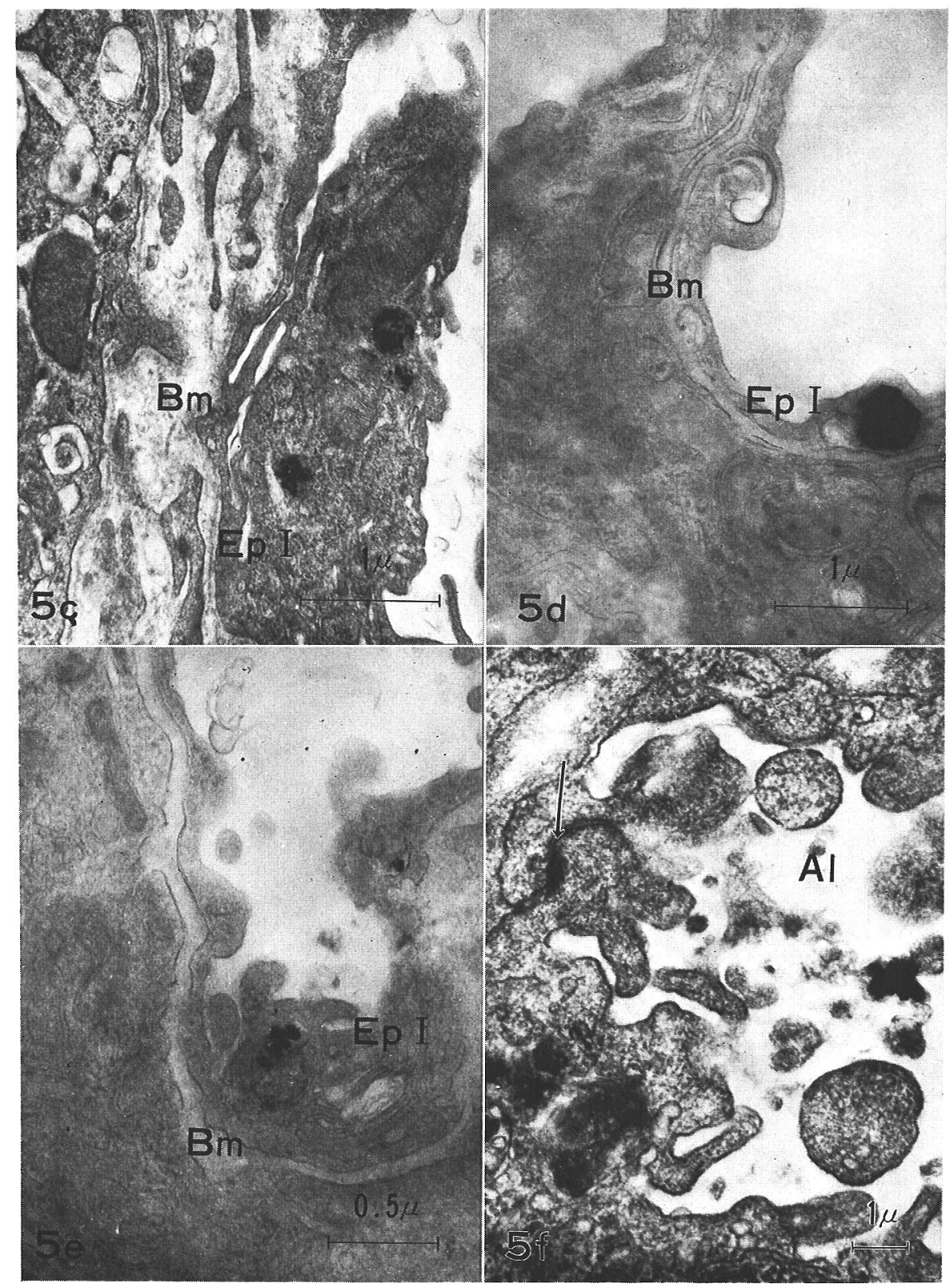

Fig. 5(c) Clusters of minute particles in lysosome-like granules. Immediately after continuous inhalation for $330 \mathrm{~min}$. (Exp. 2)

Fig. 5(d) Solitary particle in the attenuated portion of the type I epithelium. (Exp. 2, unstained)

Fig. 5(e) Cluster of minute particles in the type I epithelium. (Exp.2, unstained)

Fig. 5(f) A transformed particle in the alveolar space and a minute particle in the intercellular space of alveolar epithelia. (Exp.1, $3 \mathrm{hr}$ later) (arrows) 
H. KYONO, K. HOMMA, T. NAGATANI, T. WATANABE AND K. KAWAI

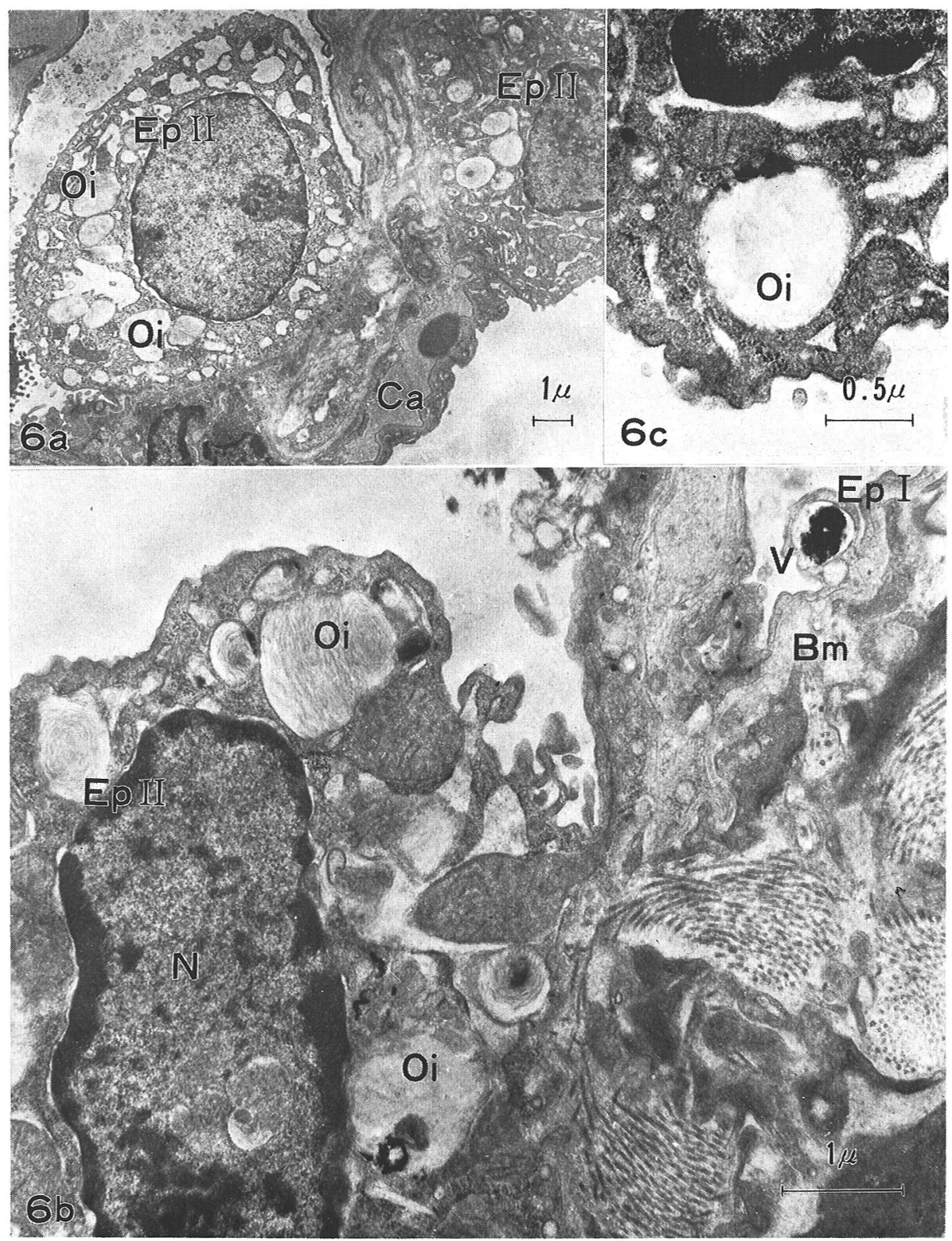

Fig. 6. Lead particles in type II alveolar epithelium.

Fig. 6(a) Vacuolation of the cytoplasm and degradation of lamellar structure of osmiophilic inclusions. (Exp. 1, $24 \mathrm{hr}$ later)

Fig. 6(b) Irregular dense particles are seen in the type II alveolar epithelium. (Exp.2) Within the large vesicle lies a partly deformed particle at the attenuated cytoplasm of type I alveolar epithelium. Notice also very narrow streaks where minute particles are located.

Fig. 6(c) Array of small particles along the membrane of osmiophilic inclusion. (Exp. 1, $3 \mathrm{hr}$ later) 


\section{LEAD PARTICLES IN LUNG}

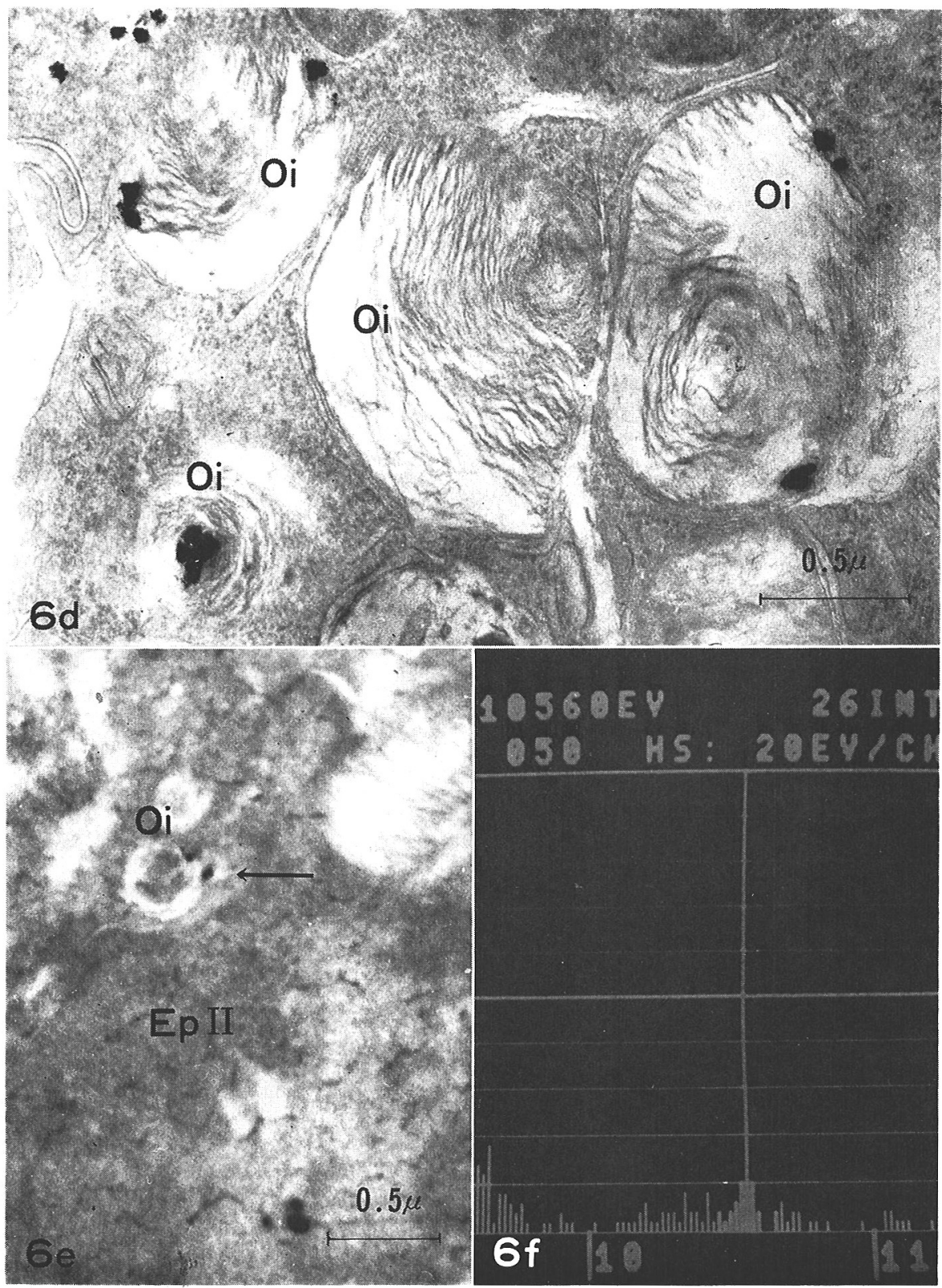

Fig. 6(d) Higher magnification of osmiophilic inclusions. (Exp. 2, unstained)

Fig. 6(e) Transmission scanning EM., unstained. Arrow indicates the point of analysis.

Fig. 6(f) Microprobe X-ray analysis for Fig.6(e). Accelerating voatage: $40 \mathrm{kV}$ Specimen current: $6 \times 10^{-11} \mathrm{~A}$. 
H. KYONO, K. HOMMA, T. NAGATANI, T. WATANABE AND K. KAWAI

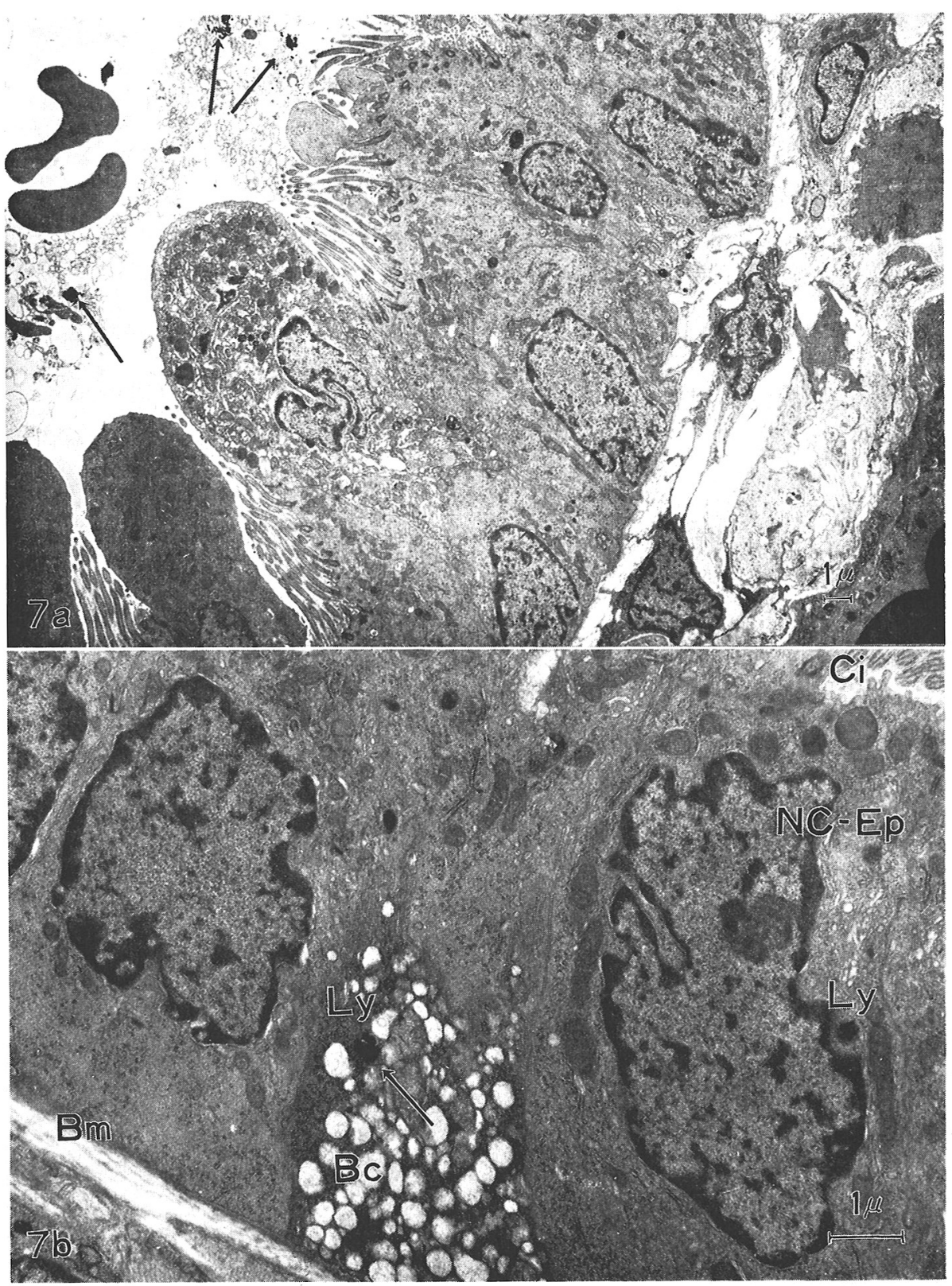

Fig. 7. Lead particles in bronchial epithelium.

Fig. 7(a) General view of peripheral bronchioles immediately after con. tinuous inhalation for $330 \mathrm{~min}$. (Exp.2) Cellular fragments and free lead particles are seen in the bronchial lumina. (arrows)

Fig. 7(b) A vacuolated basal cell with a particle larden lysosome (arrow). (Exp. 2) 


\section{LEAD PARTICLES IN LUNG}

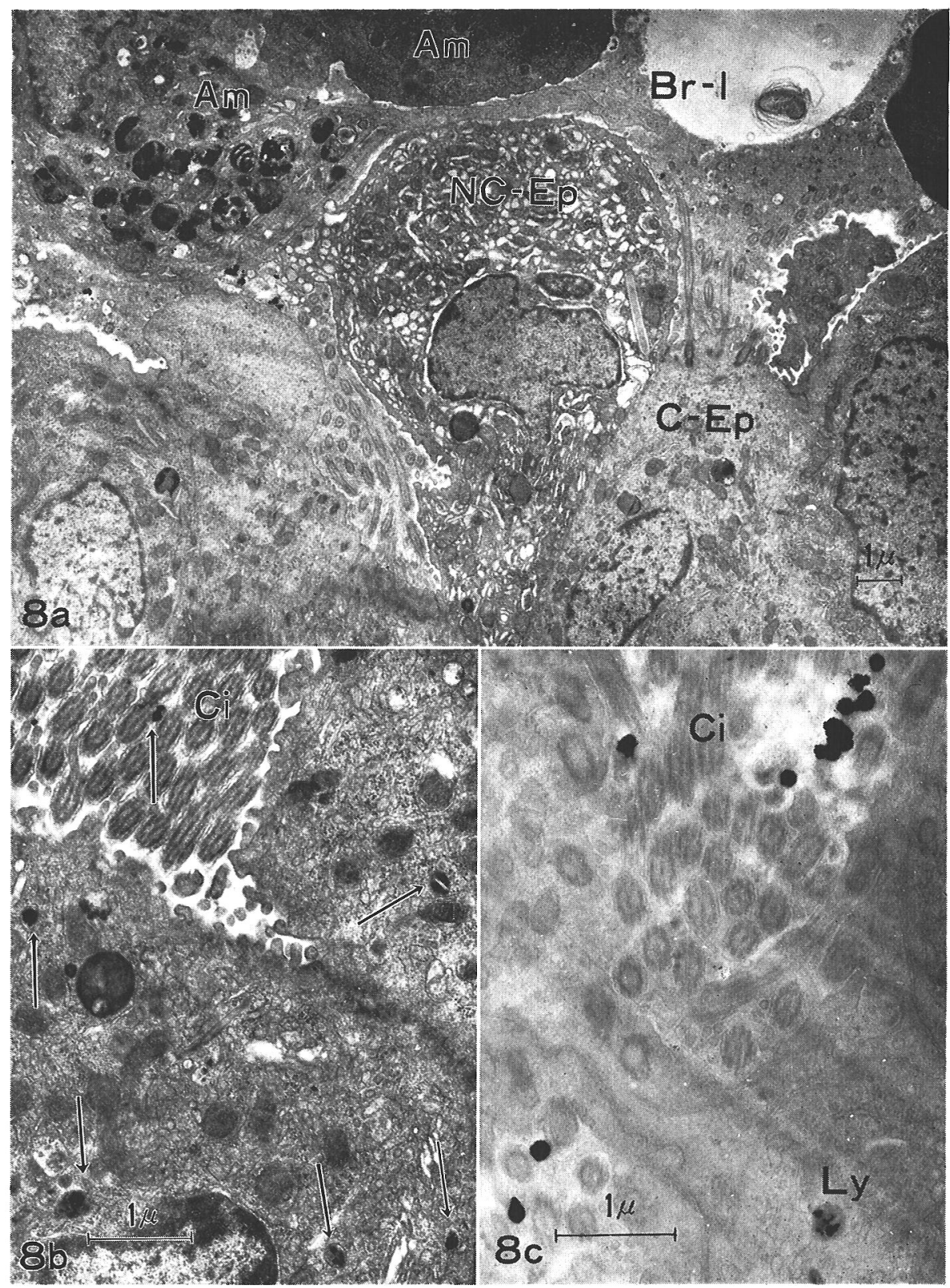

Fig. 8. Lead particles in the bronchial lumina.

Fig. 8(a) Bronchial lumina are filled with cellular exudate and particle laden macrophages. Free particles are also floating in the exudate.

Fig. 8(b) Free particles lie between the cilia. Similar particles are seen within bronchiolar epithelia (arrows).

Fig. 8(c) Solitary particles are intercalated between the cilia. (Exp. 2, unstained) 
H. KYONO, K. HOMMA, T. NAGATANI, T. WATANABE AND K. KAWAI

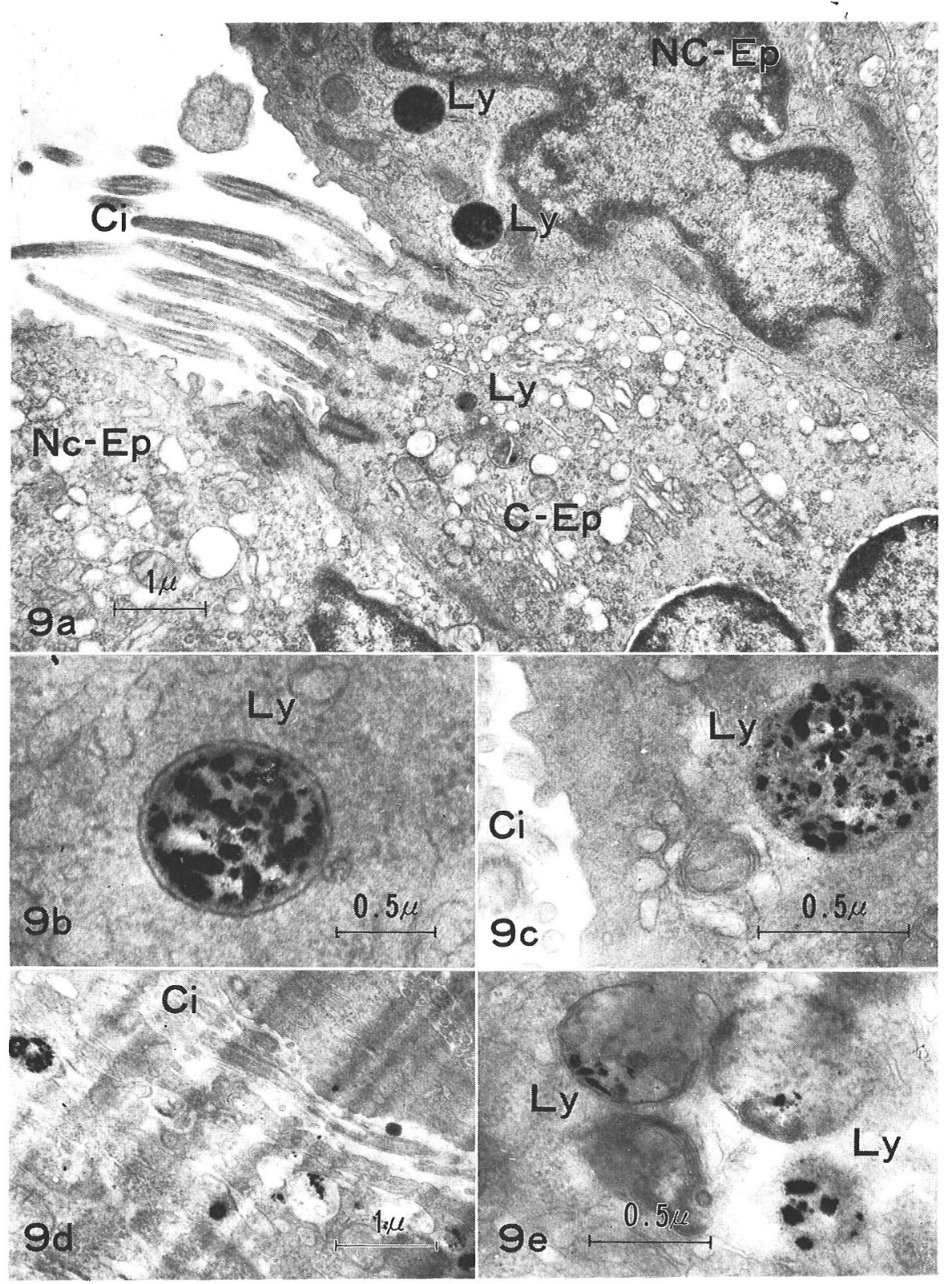

Fig. 9. Lead particles within lysosomes of bronchiolar epithelium.

Fig. 9(a) Vacuolation of the cytoplasm and particle laden lysosomes. (Exp. 2 )

Fig. 9(b) (c) Higher magnification of a lysosome with particles. (Exp.2, unstained)

Fig. 9(d) Similar aggregation of minute particles. Limiting membrane is indistinct because of unstained condition. (Exp. 2)

Fig. 9(e) Deformed particles in the lysosomes. (Exp.2, unstained) 
LEAD PARTICLES IN LUNG

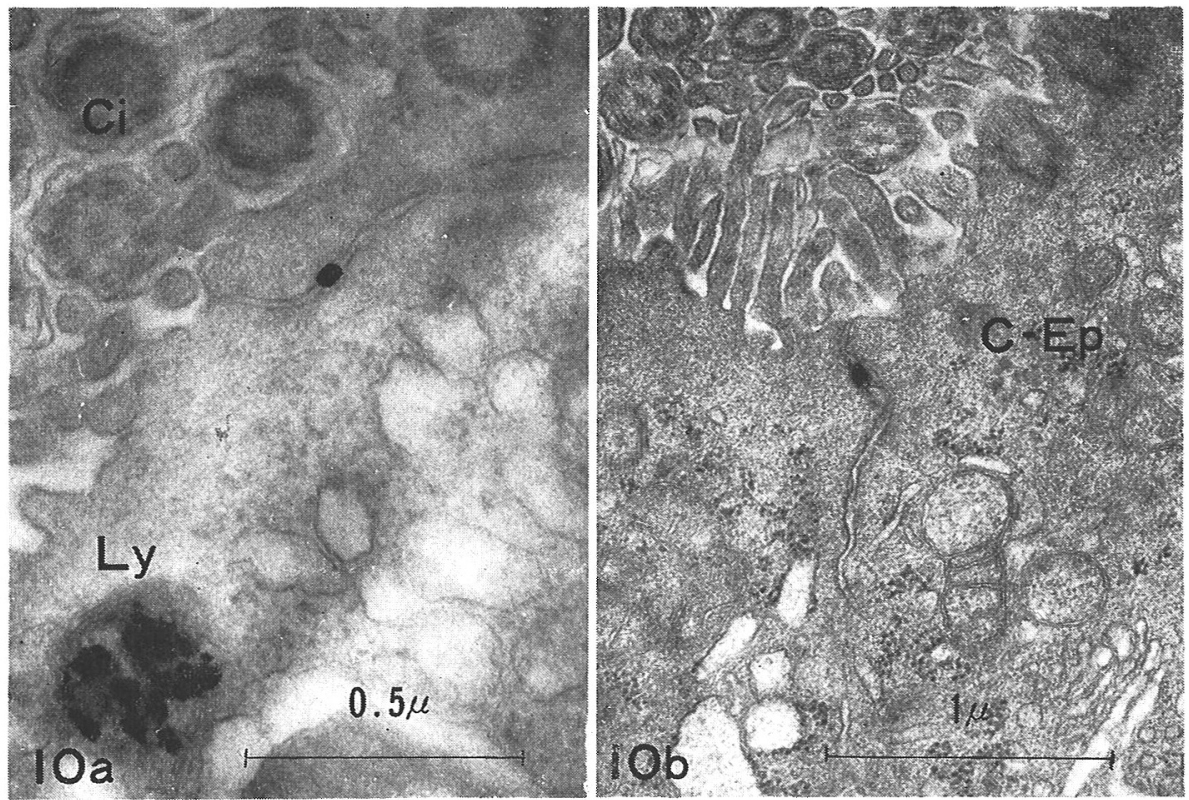

Fig. 10. A lead particle located in intercellular space of bronchial epitirena.

Fig. 10(a) Experiment 2, unstained.

Fig. 10(b) Experiment 2.

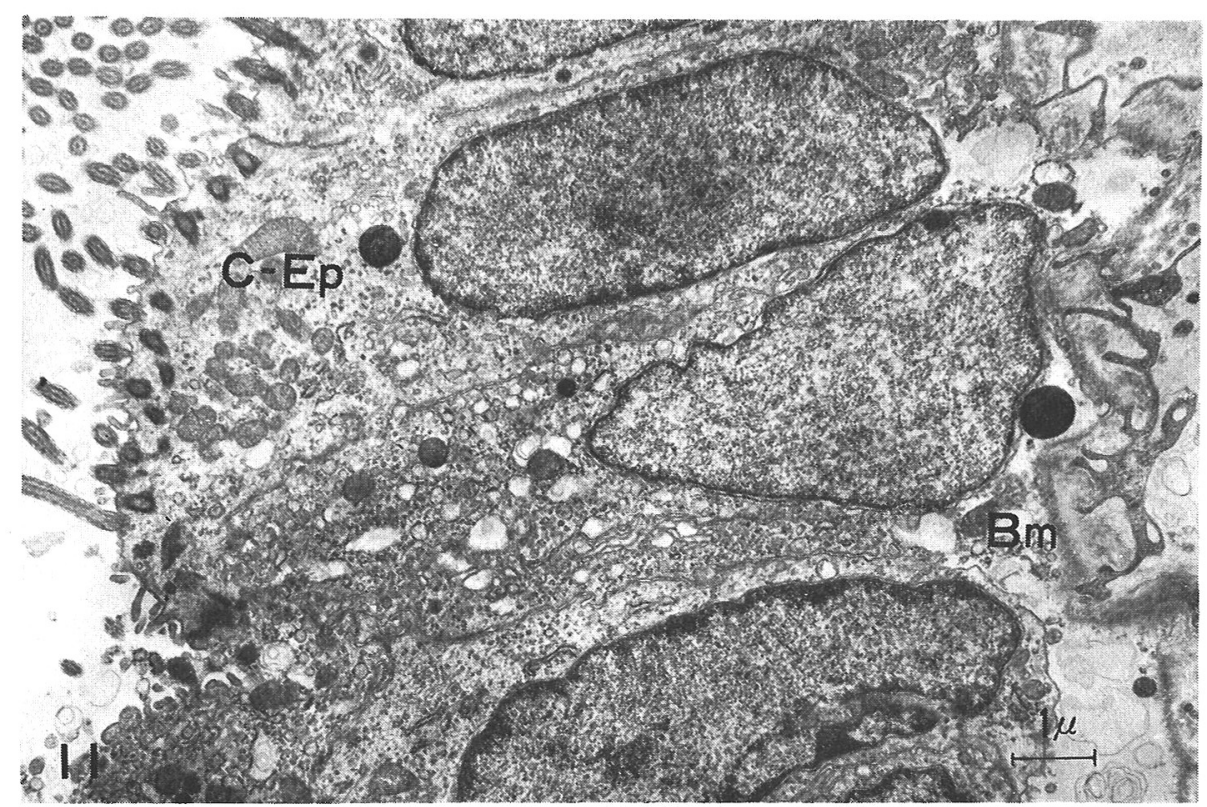

Fig. 11. Edema of bronchiolar epithelia. Immediately after continuous inhalation for $330 \mathrm{~min}$. (Exp. 2) Vacuolation of endoplasmic reticulum is also seen. 


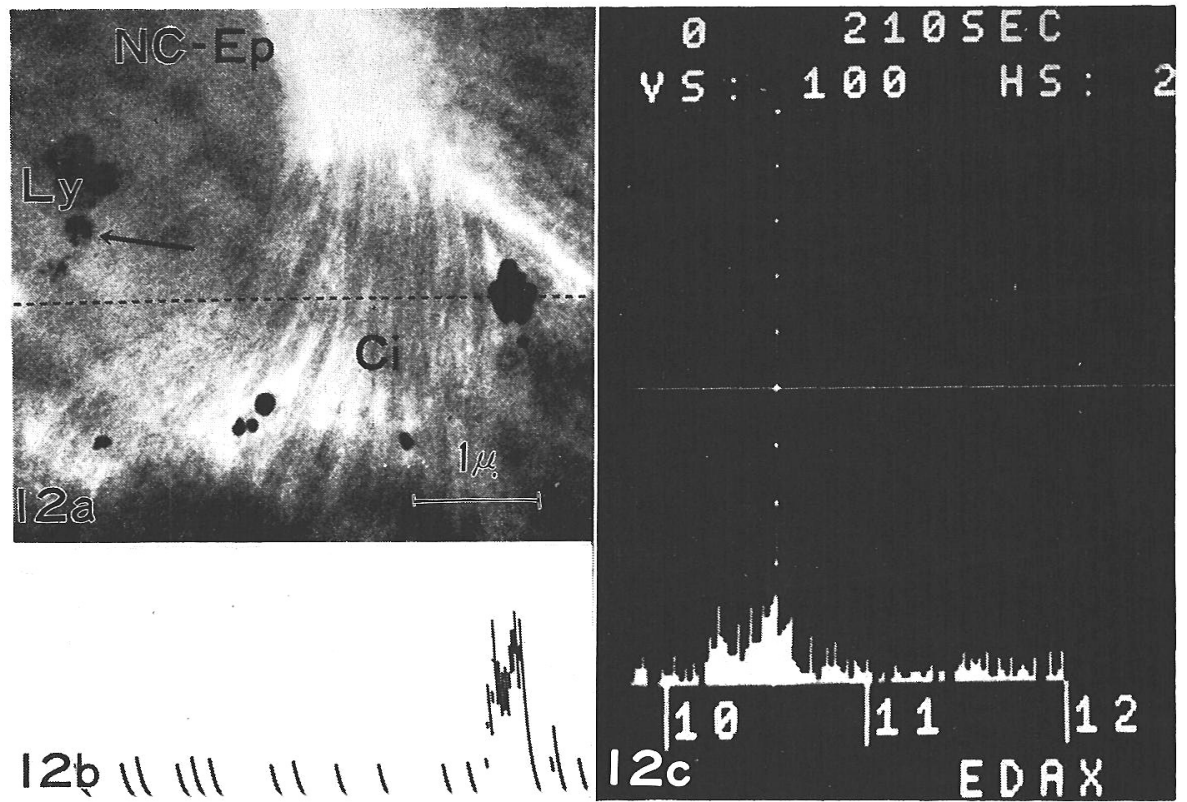

Fig. 12. X-ray microprobe analysis of lead particles deposited in the bronchioles.

Fig. 12 (a) Transmission scanning EM. Arrow indicates the point of analysis, and broken line indicates the course of line analysis.

Fig. 12(b) (c) X-ray microprobe analysis for Fig. $12(\mathrm{a})$.

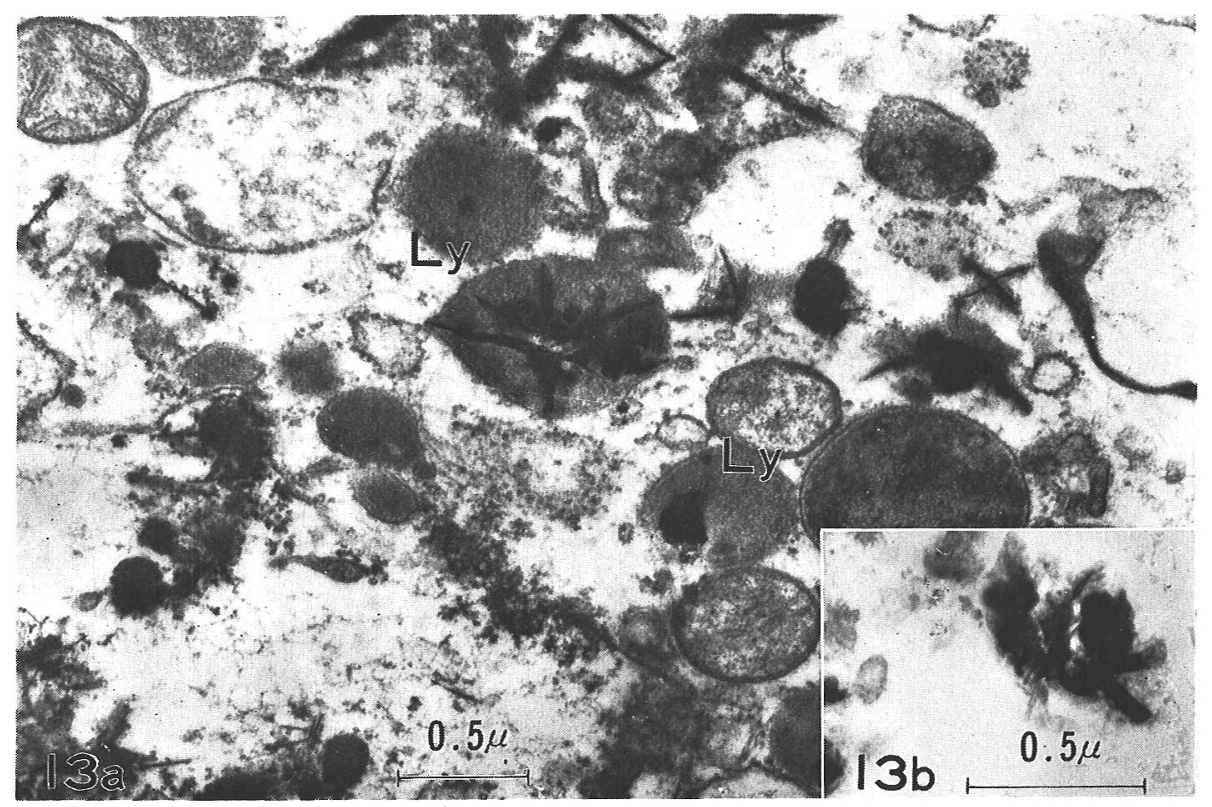

Fig. 13. Intracellular deformation of lead particle.

Fig. 13(a) Needle-like crystal formation in the lysosomes of an alveolar macrophage. (24 hr after insufflation of submicron lead fume $)^{*}$

Fig. 13(b) A small cluster of similar needle-like crystals in the present inhalation experiment. (Exp. 1)

* Cited from reference 14, through the cautesy of the authors. 